\title{
Assessment of vibrations induced in factories by automated guided vehicles
}

1 Chien-Liang Lee $\mathrm{PhD}$

Postdoctoral Fellow, Department of Civil Engineering, The University

of Hong Kong, Hong Kong, China

2. Yen-Po Wang PhD

Professor, Department of Civil Engineering, National Chiao-Tung University, Hsinchu, Taiwan
3 Ray Kai Leung Su PhD, CEng, MIStructE, MHKIE, RPE (HK), IRSE (PRC)

Associate Professor, Department of Civil Engineering, The University of Hong Kong, Hong Kong, China
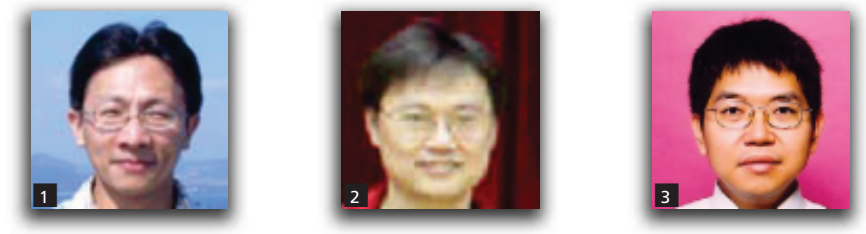

This study proposes a simplified sub-structural model to explore the floor micro-vibration induced by automated guided vehicles in thin-film transistor liquid crystal display factories. Time history analyses of a sequence of automated guided vehicles moving loads considering various car spacings on an equivalent three-span continuous beam model of a thin-film transitor liquid crystal display factory were simulated. The effectiveness of vibration control using viscoelastic dampers was also examined. Numerical simulations demonstrate that the simplified method can predict the measured floor vibration spectra with satisfactory accuracy and that the automated guided vehicles induced floor vibrations without control exceed the acceptable VC-B level required for the installation of specific precision process tools. The application of energy dissipation devices has shown to be effective in vibration mitigations as they enhance the damping characteristics of a multi-span floor system. The maximum response of the whole continuous beam induced by a group of automated guided vehicles can be effectively suppressed to a desired VC-B level if multiple viscoelastic dampers are implemented along the automated guided vehicles moving bay and the spacing between each automated guided vehicle is properly adjusted. The simplified analytical method can help engineers quickly assess the level of automated guided vehicles-induced floor vibration and assist in the design of low-vibration floor systems in high-technology factories.

\section{Notation}

A discrete-time system matrix

$\mathbf{A}^{*} \quad$ continuous-time system matrix

$A(x) \quad$ cross-sectional area

$a_{0}, a_{1}$

C

$\mathbf{C}_{\mathrm{d}}$

$c_{\mathrm{ve}}$

$\mathrm{d} x$

E

E

$\mathbf{E}^{*}$

$\mathbf{E}_{0}$

$\mathbf{E}_{1}$ coefficients of Rayleigh damping

damping matrix

contribution of damping matrix for VE damper damping coefficient of VE damper discretised element length of the beam

Young's modulus

location matrix of the moving loads

continuous-time moving load matrix

discrete-time moving load matrix of the previous time step

discrete-time moving load matrix of the current time step

engine force of AGV
$F_{\mathrm{d}}(x, t) \quad$ damper force

$F_{\max } \quad$ maximum engine force of $\mathrm{AGV}$

$f \quad$ natural frequency $(\mathrm{Hz})$

$f_{\mathrm{g} 1}, f_{\mathrm{g} 2}$, parameters of the modified Kanai-Tajimi

$\xi_{\mathrm{g} 1}, \xi_{\mathrm{g} 2} \quad$ model

$H_{1 j} \quad$ Hermitian polynomials of the modified cubic spline function

$I(x) \quad$ moment of inertia of cross-section

$J$ performance index

K stiffness matrix

$\mathbf{K}_{\mathrm{d}} \quad$ contribution of stiffness matrix for VE damper

$k_{i j} \quad$ coefficients of stiffness matrix

$k_{\mathrm{ve}} \quad$ stiffness coefficient of VE damper

$L \quad$ total length of beam

$l_{\mathrm{a}} \quad$ AGV spacing

$l_{\mathrm{w}} \quad$ distance between the two axles

M mass matrix 


$\begin{array}{ll}m_{i j} & \text { coefficients of mass matrix } \\ N & \text { number of moving loads } \\ n & \text { number of vibration modes } \\ P_{s} & \text { moving loads } \\ Q & \text { number of supports of beam } \\ \boldsymbol{q}(t) & \text { modal displacement vector } \\ q_{i}(t) & \text { ith generalised coordinate } \\ t & \text { time } \\ t_{0} & \text { time instant when moving loads come onto beam } \\ t_{\mathrm{e}} & \text { time instant when moving loads leave beam } \\ u(t) & \text { unit step function } \\ v & \text { speed of AGV } \\ \boldsymbol{w}(t) & \text { moving load vector } \\ w(x, t) & \text { displacement of beam } \\ \boldsymbol{X}\left(x_{\mathrm{d}}\right) & \text { vibration mode vector at location of VE damper } \\ X_{i}(x) & i \text { th vibration mode } \\ X_{i}^{\prime \prime}(x) & i \text { th curvature function of beam } \\ \bar{X}_{i}(x) & i \text { th assumed vibration mode } \\ \tilde{X}_{i}(x) & i \text { th modified cubic spline function } \\ x & \text { location of beam } \\ x_{\mathrm{d}} & \text { location of VE damper } \\ x_{p s}(t) & \text { location of the moving loads } \\ \boldsymbol{z}[k] & \text { state vector } \\ \Delta t & \text { sampling time } \\ \eta & \text { number of VE dampers } \\ \theta_{i j} & \text { rotation of beam } \\ \xi & \text { damping ratio } \\ \omega & \text { natural angular frequency (rad/s) }\end{array}$

\section{Introduction}

The development of thin-film transistor liquid crystal display (TFT-LCD) (Jang and Choi, 2006) has become one of the fastest growing industries in the past decade because of the strong market demand for products such as displays for computers, mobile telephones, digital cameras and flat-screen televisions. The TFT-LCD industry specialises in glass substrates as opposed to silicon wafers, which are used in the semiconductor industry, but adopts similar micro-vibration criteria, fabrication processes and equipment. The manufacturing processes of silicon wafers and glass panels are susceptible to a variety of interior and exterior vibration sources. Significant interior vibration sources include pumps, motors, carts, servo robots, conveying systems, personnel walking and automated material handling systems (Jang and Choi, 2006). Exterior ground-borne sources may include supply mechanical equipment in neighbouring buildings, nearby traffic, rail lines (high-speed trains) and pile construction. If the ambient floor vibration does not meet specified vibration criteria, the desired production yield of the chips or displays will not be achieved.

The Bolt, Beranek and Newman (BBN) vibration criterion (VC) is one of the most popular criteria used for vibration-sensitive equipment in high-tech industries (Gordon, 1991). The VC curves are a set of velocity spectra (called VC-A, VC-B, VC-C, VC-D and VC-E) that correspond to the allowable root mean square (RMS) velocity from $2000 \mu$-inch/s to $125 \mu$-inch/s within a frequency ranging from 8 to $100 \mathrm{~Hz}$. For frequencies below $8 \mathrm{~Hz}$, the VC curves allow for greater vibration velocity because this frequency range lies below the lowest natural (resonance) frequency of most of the equipment, as indicated by Gordon (1991). The desired floor vibration level for installing process tools depends on the fabrication precision of the production line widths. For example, the criterion suggests that the VC-B level $(1000 \mu$-inch/s) is an appropriate standard for $1000 \times$ magnification optical microscopes, inspection and lithography equipment for $3 \mu \mathrm{m}$ line width, while a stringent VC-C level $(500 \mu$-inch/s) is preferable for higher precision lithographic and inspection equipment including electron microscopes for $1 \mu \mathrm{m}$ line width. Normally, VC-B or VC-C levels are acceptable for most vibration-sensitive tools required by TFT-LCD manufacturers. A review of practical papers and reports with information on micro-vibration sources, criteria, measurements and mitigations can be found at http://www.colingordon.com/papers_body.html.

Over the last two decades, micro-vibrations have been extensively studied in the context of both human comfort and production yields for office buildings, biotechnology/metrology labs and semiconductor factories (Ju, 2009; Pan et al., 2001, 2008; Pavic and Reynolds, 2002, 2003; Ungar and White, 1979; Ungar et al., 2004; Willford et al., 2005; Xu and Guo, 2006; Xu and Hong, 2008; Xu et al., 2004; Yang and Agrawal, 2000; Živanović and Pavić, 2009). Vibration control using passive or active isolation devices underneath precision equipment has also been widely explored (Ismail et al., 2009; Kim and Amick, 1997; Nakamura et al., 1999; Xu et al., 2003a, 2003b, 2004; Yang and Agrawal, 2000; Yang et al., 2003; Yoshioka et al., 2001).

Most studies presented in the literature have focused on floor vibrations induced by exterior ground-borne traffic (train) excitations or from personnel walking, and mechanical disturbance sources inside a building. However, adverse vibrations that are directly induced by moving vehicles on the production floor in industrial factories have rarely been considered in the design phase. As a consequence, most TFT-LCD factories encounter interior vehicle-induced floor vibration problems (Lee et al., 2012) when they begin operations. Figure 1 illustrates a typical TFT-LCD building with two clean rooms. A reinforced concrete (RC) waffle slab (Howard and Hansen, 2003) supported by two-way grillage beams of depth $1.2 \mathrm{~m}$ or a flat RC slab ('cheese' slab) of thickness $0 \cdot 6-0.8 \mathrm{~m}$ supported by longspan steel mega trusses are often adopted in order to minimise micro-vibrations.

Several empirical formulae to describe the relation between floor stiffness and maximum velocity vibration have been proposed to design a stiff and low-vibration floor system for advanced technology facilities. Ungar and White (1979) proposed a semiempirical model to relate the footfall-induced maximum onethird octave band RMS velocity amplitudes to vertical floor stiffness and the fundamental frequency. In this equation, the 


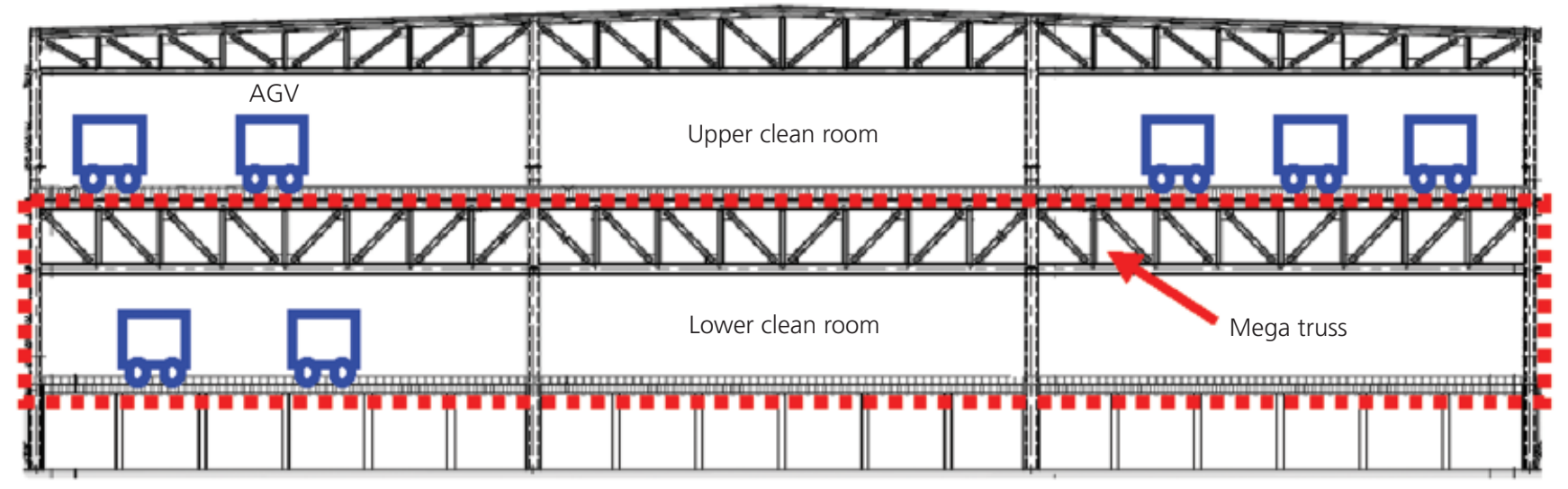

Figure 1. Elevation view of typical double clean-room building

(Lee et al., 2012)

maximum velocity is inversely proportional to the stiffness and an empirical coefficient, which is proportional to the vibration amplitude, is determined using measured data obtained from different persons walking on a variety of floors at 100 paces per minute. Moreover, when using the simplified model, corrections can be made to adjust for walkers of different weights and walking speeds.

Gordon (1987), Amick et al. (1991) and Amick and Bayat (1998) also developed a similar formula to predict the maximum floor velocity vibrations primarily induced by mechanical excitations such as the turbulence in piping and ducting connected to the floors. The relation between mid-bay floor stiffness and maximum floor velocity is determined using the measured data of a collection of floors through statistical regression analyses. These simplified methods are useful in the early design phase of floor systems, but vibration induced by moving vehicles on production floors has not been explored in these studies.

At present, the transportation of glass panels between processing tools in TFT-LCD factories is generally accomplished by automated guided vehicles (AGVs, http://www.muratec.net/mac/products/fpd/agv.html), rail guided vehicles (RGVs) and stockers (Jang and Choi, 2006). AGVs, RGVs and stockers have been found to induce considerably more significant floor micro-vibrations than walking personnel or nearby traffic, and this problem has become more serious in the TFT-LCD industry as increasingly larger glass panels are being manufactured. The objective of this study is, therefore, to propose a simplified and effective sub-structural beam model that will quickly assess AGV-induced micro-vibration on production floors for the conceptual design phase or evaluate vibration control performance by the introduction of dampers.

Dynamic analysis of beams and bridges under moving loads resulting from vehicles and trains is well developed (Lee, 1996;
Wu, 2003; Wu and Dai, 1987; Wu and Shih, 2000; Yang and Lin, 1995; Yang and Yao, 1997; Yang et al., 2004; Yao and Yang, 2006; Zheng et al., 1998) and is adopted in this study. To simplify the task in a conservative sense, the multi-span cheese floor of a single bay (AGV moving bay) of a factory is treated as an equivalent sub-structural multi-span continuous beam (Figure 2) by adjusting its flexural rigidity such that the fundamental frequency of the beam model is close to the in situ measured first-mode floor vibration frequency. The modified beam vibration functions (MBVF) proposed by Zheng et al. (1998) are then further adopted for the modelling of the sub-structural system. The dynamic response of the system is resolved using a statespace procedure (Lopez-Almansa et al., 1988; Wang et al., 2001) algorithm that preserves the dynamic characteristics of the system without distortion. Moreover, a modified Kanai-Tajimi model (Yang and Agrawal, 2000) is adopted in this paper to simulate the AGV engine force. A numerical simulation of a group of AGVs moving on the three-span floor system is performed to predict the floor micro-vibration level and takes into account the effect of different spacings between any two consecutive AGVs. Finally, the effectiveness of vibration control (Housner et al., 1997; Soong and Dargush, 1997) by the introduction of viscoelastic (VE) (Lee et al., 2005; Yohei et al., 2003) dampers is also examined and discussed.

\section{Review of dynamic analysis of multi-span beams under moving loads by MBVF}

The vertical displacement of a beam, $w(x, t)$, can be represented in terms of modal contributions as

1. $w(x, t)=\sum_{i=1}^{n} q_{i}(t) X_{i}(x)$

where $n$ is the number of vibration modes that are considered 

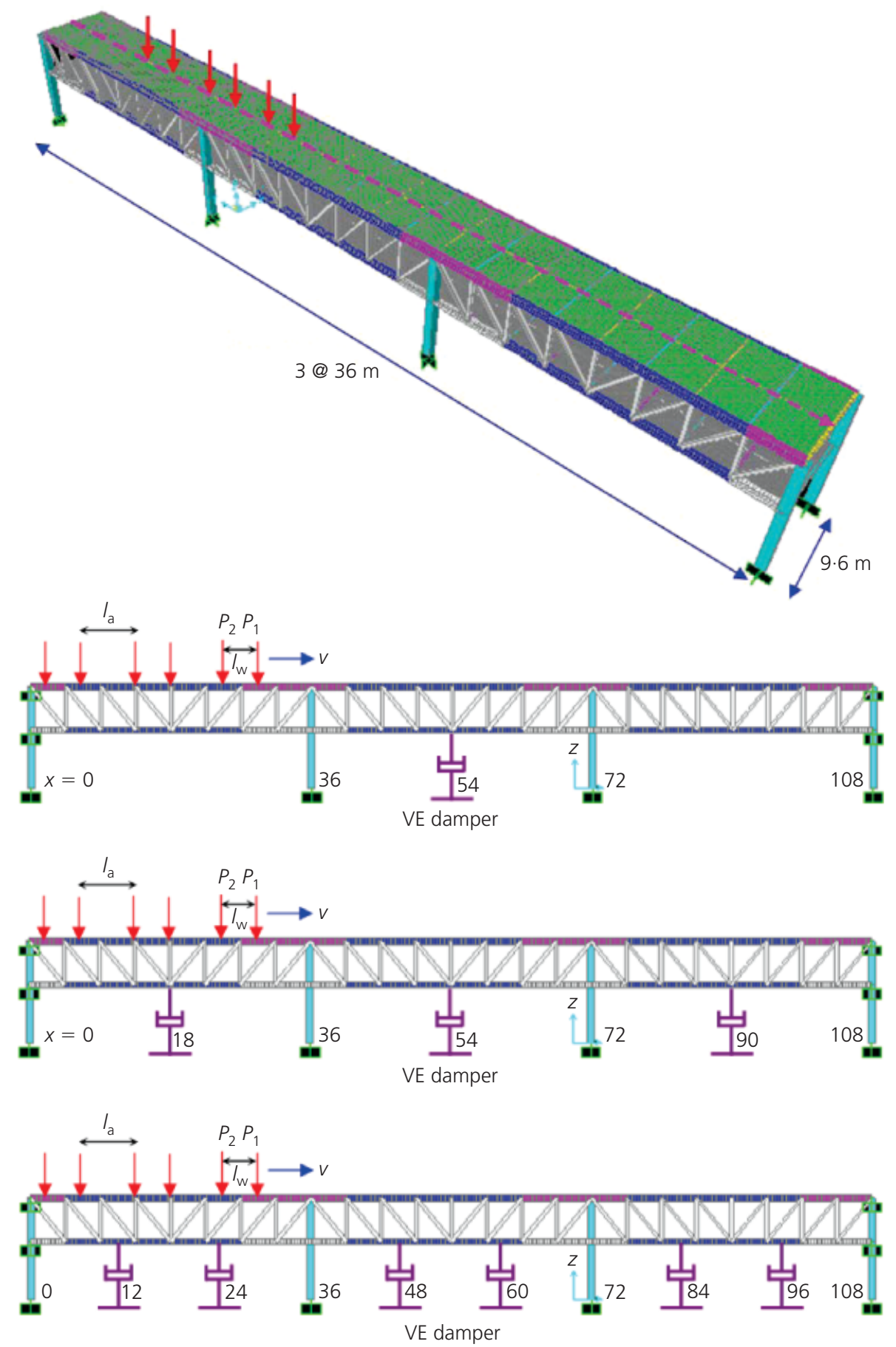

Figure 2. Illustration of AGV moving loads on an equivalent three-span beam model (Lee et al., 2012)

when calculating the dynamic responses, $q_{i}(t)$ is the $i$ th generalised coordinate and $X_{i}(x)$ is the $i$ th vibration mode that satisfies the boundary conditions of the supports. The equation defining the motion of an undamped Bernoulli-Euler beam with $(Q+1)$ supports subjected to $N$ moving loads can be presented as (Zheng et al., 1998) $\sum_{j=1}^{n} m_{i j} \ddot{q}_{j}(t)+\sum_{j=1}^{n} k_{i j} q_{j}(t)$

$=\sum_{s=1}^{N} P_{s} X_{i}\left[x_{p s}(t)\right]\left[u\left(t-t_{0}\right)-u\left(t-t_{e}\right)\right]$

2. $\quad i=1,2, \cdots, n$ 
in which $x_{p s}(t)$ is the location of the moving loads $\left(P_{\mathrm{s}}\right), t_{0}$ and $t_{\mathrm{e}}$ are the time instants when the moving loads come onto and leave the beam, respectively, $u(t)$ is the unit step function defined as

$$
\text { 3. } u(t)= \begin{cases}1 & t \geqslant 0 \\ 0 & t<0\end{cases}
$$

and

4a. $m_{i j}=\int_{0}^{L} \rho A(x) X_{i}(x) X_{j}(x) \mathrm{d} x$

4b. $k_{i j}=\int_{0}^{L} E I(x) X_{i}^{\prime \prime}(x) X_{j}^{\prime \prime}(x) \mathrm{d} x$

where $\rho$ is the density, $E$ is Young's modulus, $A(x)$ is the crosssectional area, $I(x)$ is the moment of inertia of the cross-section and $X_{i}^{\prime \prime}(x)$ denotes the curvature of the beam.

The vibration modes of a multi-span beam can be obtained by using the vibration modes of a single-span beam that have been modified by cubic spline functions as follows (Zheng et al., 1998)

5. $\quad X_{i}(x)=\bar{X}_{i}(x)+\tilde{X}_{i}(x)$

where $\bar{X}_{i}(x)$ is the $i$ th assumed vibration mode of a multi-span beam that has a total length $L$ (with the same boundary conditions of end supports, but without the intermediate supports) and $\tilde{X}_{i}(x)$ is the modified cubic spline function, which makes each $X_{i}(x)$ satisfy the boundary conditions at both ends and also at the intermediate supports without deflections. The assumed vibration modes are the Fourier sine series of a simply supported beam of total length $L$ given as

6. $\bar{X}_{i}(x)=\sin \left(\frac{i \pi x}{L}\right), i=1,2, \ldots, n$

On the other hand, the calculation processes of the modified cubic spline function $\tilde{X}_{i}(x)$ of a continuous beam, which satisfies boundary conditions such as zero displacement at each support and zero curvature at two simply-supported ends, are provided by Zheng et al. (1998) as

$$
\begin{aligned}
\tilde{X}_{i}(x)= & H_{1 j}\left(\xi_{j}\right) y_{i(j-1)}+H_{2 j}\left(\xi_{j}\right) \theta_{i(j-1)} \\
& +H_{3 j}\left(\xi_{j}\right) y_{i j}+H_{4 j}\left(\xi_{j}\right) \theta_{i j}
\end{aligned}
$$

7. $x \in\left[x_{j-1}, x_{j}\right], j=1,2, \ldots, Q$

where

$$
\begin{aligned}
y_{i j} & =\tilde{X}_{i}\left(x_{j}\right)=-\bar{X}_{i}\left(x_{j}\right), \theta_{i j}=\tilde{X}_{i}^{\prime}\left(x_{j}\right), \\
\text { 8. } \quad i & =1,2, \ldots, n, j=1,2, \ldots, Q
\end{aligned}
$$

9b. $H_{2 j}\left(\xi_{j}\right)=l_{j} \xi_{j}\left(1-\xi_{j}\right)^{2}$

9c. $\quad H_{3 j}\left(\xi_{j}\right)=3 \xi_{j}^{2}-2 \xi_{j}^{3}$

9d. $H_{4 j}\left(\xi_{j}\right)=l_{j} \xi_{j}^{2}\left(\xi_{j}-1\right)$

$\xi_{j}=\left(x-x_{j-1}\right) / l_{j}, l_{j}=x_{j}-x_{j-1}$,

9e. $\quad j=1,2, \ldots, Q$

The coefficients $y_{i j}$ are known from Equations 6 and 8, while $\theta_{i j}$ are further determined by the continuity of the second derivative at the intermediate point supports (Zheng et al., 1998). This modelling technique is adopted for the clean-room floor represented by an equivalent multi-span continuous beam in this study.

\section{State-space procedure algorithm}

Equation 2 can be further elaborated in matrix formation as

10a. $\mathbf{M} \ddot{\boldsymbol{q}}(t)+\mathbf{C} \dot{\boldsymbol{q}}(t)+\mathbf{K} \boldsymbol{q}(t)=\mathbf{E} \boldsymbol{w}(t)$

where $\mathbf{M}=\left[m_{i j}\right]$ is the $n \times n$ mass matrix with the coefficients shown in Equation $4 \mathrm{a}, \mathbf{K}=\left[k_{i j}\right]$ is the $n \times n$ stiffness matrix with the coefficients shown in Equation $4 \mathrm{~b}, \mathbf{C}$ is the $n \times n$ damping matrix determined by the damping ratios assigned to each vibration mode considered in the analysis and by the eigenvectors obtained from the $\mathbf{M}$ and $\mathbf{K}$ matrices. Furthermore, 
10b. $\quad \boldsymbol{q}(t)=\left[\begin{array}{c}q_{1}(t) \\ q_{2}(t) \\ \vdots \\ q_{n}(t)\end{array}\right]$

is the $n \times 1$ modal displacement vector

10c. $\quad \mathbf{E}=\left[\begin{array}{cccc}X_{1}\left[x_{p 1}(t)\right] & X_{1}\left[x_{p 2}(t)\right] & \cdots & X_{1}\left[x_{p N}(t)\right] \\ X_{2}\left[x_{p 1}(t)\right] & X_{2}\left[x_{p 2}(t)\right] & \cdots & X_{2}\left[x_{p N}(t)\right] \\ \vdots & \vdots & \ddots & \vdots \\ X_{n}\left[x_{p 1}(t)\right] & X_{n}\left[x_{p 2}(t)\right] & \cdots & X_{n}\left[x_{p N}(t)\right]\end{array}\right]$

is the $n \times N$ location matrix of the moving loads on the beam and

10d. $\quad \boldsymbol{w}(t)=\left[\begin{array}{c}P_{1}(t) \\ P_{2}(t) \\ \vdots \\ P_{N}(t)\end{array}\right]$

is the $N \times 1$ moving load vector.

The analytical solution to Equation 10a can be obtained by the recursive difference state-space equation (Lopez-Almansa et al., 1988; Wang et al., 2001)

11a. $\boldsymbol{z}[k]=\mathbf{A} \boldsymbol{z}[k-1]+\mathbf{E}_{0} \boldsymbol{w}[k-1]+\mathbf{E}_{1} \boldsymbol{w}[k]$

In this equation

11b. $z[k]=\left[\begin{array}{l}\boldsymbol{q}[k] \\ \dot{\boldsymbol{q}}[k]\end{array}\right]$

is the $2 n \times 1$ state vector,

11c. $\mathbf{A}=\mathrm{e}^{\mathbf{A}^{*} \Delta t}$

is the $2 n \times 2 n$ discrete-time system matrix and $\Delta t$ is the sampling time.

11d. $\mathbf{A}^{*}=\left[\begin{array}{cc}\mathbf{0} & \mathbf{I} \\ -\mathbf{M}^{-1} \mathbf{K} & -\mathbf{M}^{-1} \mathbf{C}\end{array}\right]$

is the $2 n \times 2 n$ continuous-time system matrix, 11e. $\mathbf{E}_{0}=\left[\left(\mathbf{A}^{*}\right)^{-1} \mathbf{A}+\frac{1}{\Delta t}\left(\mathbf{A}^{*}\right)^{-2}(\mathbf{I}-\mathbf{A})\right] \mathbf{E}^{*}$

is the $2 n \times N$ discrete-time moving load matrix of the previous time step,

11f. $\mathbf{E}_{1}=\left[-\left(\mathbf{A}^{*}\right)^{-1}+\frac{1}{\Delta t}\left(\mathbf{A}^{*}\right)^{-2}(\mathbf{A}-\mathbf{I})\right] \mathbf{E}^{*}$

is the $2 n \times N$ discrete-time moving load matrix of the current time step and

11g. $\mathbf{E}^{*}=\left[\begin{array}{c}\mathbf{0} \\ -\mathbf{M}^{-1} \mathbf{E}\end{array}\right]$

is the $2 n \times N$ continuous-time moving load matrix.

\section{Assessment of AGV-induced floor vibration}

\subsection{The target TFT-LCD facility and its modelling}

The TFT-LCD building illustrated in Figure 1 is considered in the study. Since the vertical floor vibration is in essence a localised behaviour of the structure and the vibration is most pronounced along the AGV moving path (bay), a sub-structure of a three-span continuous beam subjected to moving loads (as shown in Figure 2) is considered to be adequate. The $9.6 \mathrm{~m}$ wide mega truss spans $36 \mathrm{~m}$ equally in each bay. It supports a RC cheese slab of thickness $0.55 \mathrm{~m}$, giving a mass per unit length of $\rho A=9.1505 \times 10^{3} \mathrm{~kg} / \mathrm{m}$ (with air circulation holes) and an equivalent flexural rigidity of $E I=2.3097 \times 10^{11} \mathrm{Nm}^{2}$ (Lee et al., 2012), so that the fundamental frequency of the three-span continuous beam is around $6 \cdot 1 \mathrm{~Hz}$. The first five natural frequencies of the equivalent threespan continuous beam determined from eigenanalysis of the mass and stiffness matrices are summarised in Table 1. Moreover, a 5\% damping ratio is assumed for each vibration mode.

\subsection{Simulation of AGV engine forces}

The total static weight of the AGV vehicle considered is $P=2200 \mathrm{kgf}$ with a distance between the two axles of $l_{\mathrm{w}}=1.2 \mathrm{~m}$. A modified Kanai-Tajimi power spectral density (PSD) function (Yang and Agrawal, 2000) is adopted in this study to simulate the engine force in a frequency domain format as

$$
\begin{aligned}
F(f)= & \frac{\left[1+4 \xi_{g 1}^{2}\left(f / f_{\mathrm{g} 1}\right)^{2}\right]\left(f / f_{\mathrm{g} 2}\right)^{2} S_{0}^{2}}{\left\{\left[1-\left(f / f_{\mathrm{g} 1}\right)^{2}\right]^{2}+4 \xi_{\mathrm{g} 1}^{2}\left(f / f_{\mathrm{g} 1}\right)^{2}\right\}} \\
12 . \quad & \times\left\{\left[1-\left(f / f_{\mathrm{g} 2}\right)^{2}\right]^{2}+4 \xi_{\mathrm{g} 2}^{2}\left(f / f_{\mathrm{g} 2}\right)^{2}\right\}
\end{aligned}
$$

where $f_{\mathrm{g} 1}, f_{\mathrm{g} 2}, \xi_{\mathrm{g} 1}$ and $\xi_{\mathrm{g} 2}$ are the constant parameters (where $f_{\mathrm{g} 1}$ and $f_{\mathrm{g} 2}$ control the predominant frequency contents of the engine 


\begin{tabular}{lccccc}
\hline \multirow{2}{*}{$\begin{array}{l}\text { Number of } \\
\text { VE dampers }\end{array}$} & \multicolumn{5}{c}{ Frequency: Hz } \\
\cline { 2 - 6 } & $f_{1}$ & $f_{2}$ & $f_{3}$ & $f_{4}$ & $f_{5}$ \\
\hline 0 & 6.089 & 7.804 & 11.395 & 24.357 & 27.759 \\
1 & 6.757 & 7.804 & 10.652 & 24.357 & 27.684 \\
3 & 6.139 & 7.873 & 11.509 & 24.357 & 27.631 \\
6 & 6.091 & 7.806 & 11.399 & 24.502 & 27.932 \\
\hline
\end{tabular}

\begin{tabular}{rrrrrr}
\hline \multicolumn{5}{c}{ Damping ratio: \% } \\
\cline { 2 - 6 } & $\xi_{1}$ & $\xi_{2}$ & \multicolumn{1}{c}{$\xi_{3}$} & $\xi_{4}$ & \multicolumn{1}{c}{$\xi_{5}$} \\
\hline 0 & 5.00 & 5.00 & 5.00 & 5.00 & 5.00 \\
1 & 23.29 & 5.00 & 28.42 & 5.00 & 6.08 \\
3 & 61.00 & 49.44 & 38.05 & 5.00 & 6.60 \\
6 & 88.28 & 70.08 & 49.86 & 25.97 & 24.13
\end{tabular}

Table 1. First five modal parameters of the three-span continuous floor system with and without VE dampers

excitation) and $S_{0}$ is the force intensity. Figure 3 shows a comparison between the simulated and in situ floor vibration spectra at $x=45 \mathrm{~m}$ of the target TFT-LCD factory, in which the simulated and measured vibration spectra are consistent and comparable if a maximum engine force of $F_{\max }=150 \mathrm{kgf}$ with frequency parameters $f_{\mathrm{g} 1}=5 \mathrm{~Hz}$ and $f_{\mathrm{g} 2}=30 \mathrm{~Hz}$ (with $S_{0}=1 \cdot 0, \xi_{\mathrm{g} 1}=0.7$ and $\xi_{\mathrm{g} 2}=0.6$ ), and maximum engine force of $F_{\max }=300 \mathrm{kgf}$ with frequency parameters $f_{\mathrm{g} 1}=5 \mathrm{~Hz}$ and $f_{\mathrm{g} 2}=50 \mathrm{~Hz}$ (with $S_{0}=1.0$, $\xi_{\mathrm{g} 1}=0.7$ and $\xi_{\mathrm{g} 2}=0.6$ ) for the modified Kanai-Tajimi model are adopted, respectively. This allows us to derive the input engine force time histories (Figure 4) for dynamic analyses with AGV speeds $(v)$ of 1.0 and $2.0 \mathrm{~m} / \mathrm{s}$. The results reveal that the intensity and the predominant frequency content of AGV engine forces increase with AGV speed. As a result, the AGV-induced peak floor vibration and the most seriously contaminated bandwidth tend to increase with AGV speed, as shown in Figure 3(a). Moreover, in order to investigate the accuracy of the results obtained by considering constant damping ratios (5\%) for each vibration mode used in this paper, the floor vibration spectra at $x=45 \mathrm{~m}$ of the central span obtained using Rayleigh damping are illustrated in Figure 5. The Rayleigh damping matrix can be represented as (Chopra, 1995)

13. $\mathbf{C}=a_{0} \mathbf{M}+a_{1} \mathbf{K}$

where the coefficients $a_{0}$ and $a_{1}$ can be determined from the prespecified damping ratios $\xi_{i}$ and $\xi_{j}$ for the $i$ th and $j$ th modes by solving the following algebraic equations

14. $\frac{1}{2}\left[\begin{array}{ll}1 / \omega_{i} & \omega_{i} \\ 1 / \omega_{j} & \omega_{j}\end{array}\right]\left\{\begin{array}{l}a_{0} \\ a_{1}\end{array}\right\}=\left\{\begin{array}{l}\xi_{i} \\ \xi_{j}\end{array}\right\}$

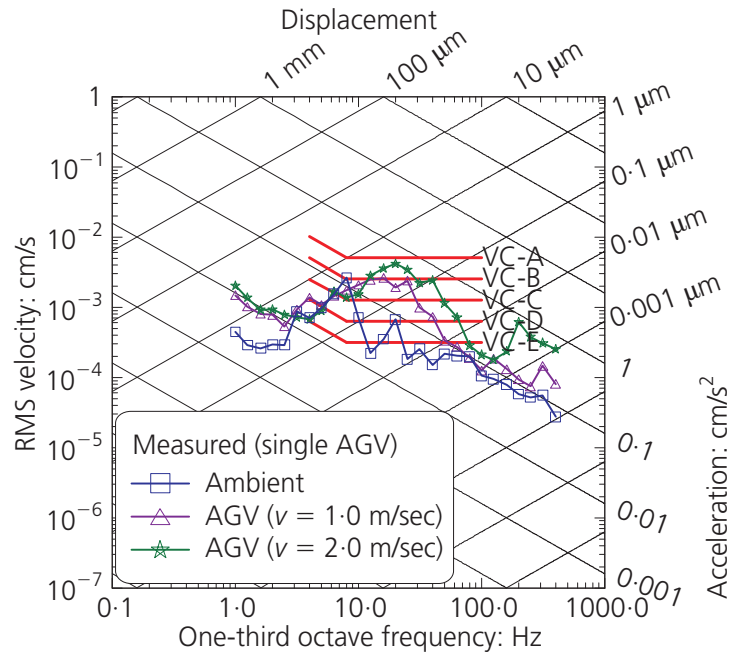

(a)

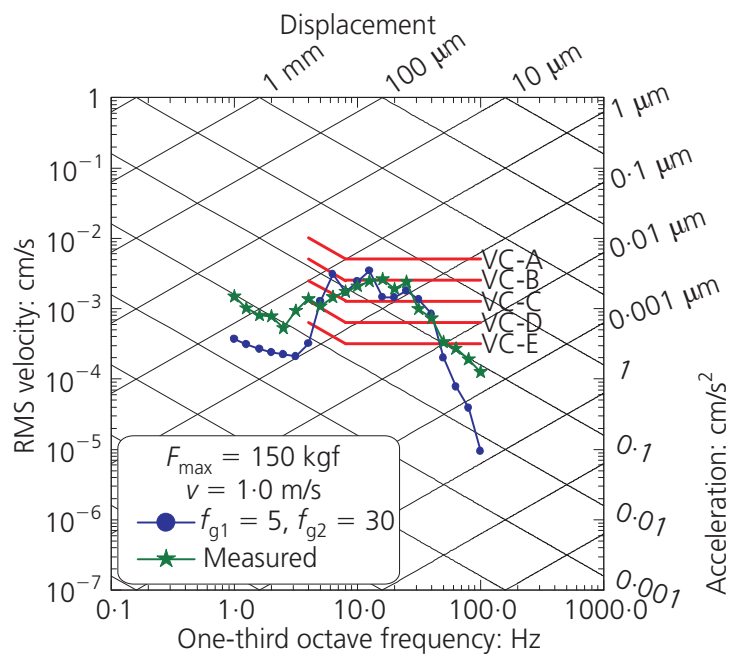

(b)

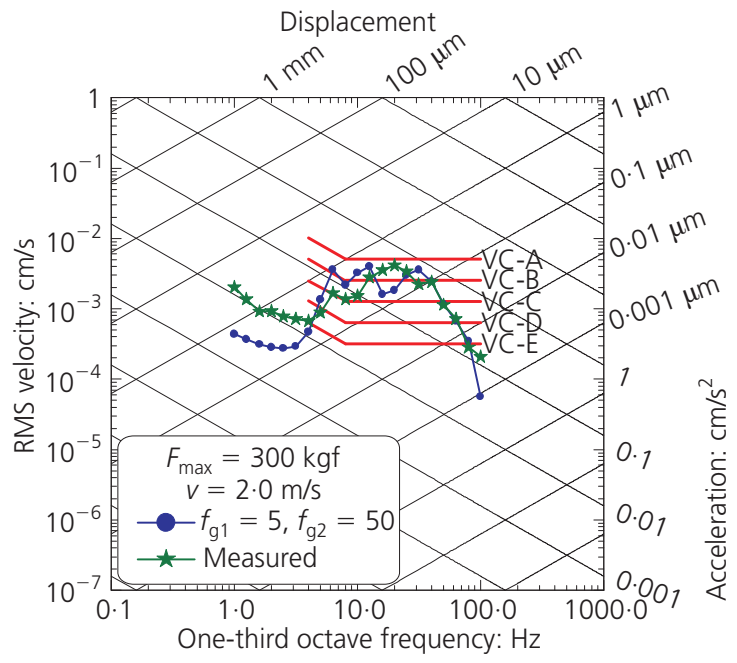

(c)

Figure 3. Measured and simulated floor vibration spectrum at $x=45 \mathrm{~m}$ : (a) measured; (b) simulated $(v=1.0 \mathrm{~m} / \mathrm{s})$; (c) simulated $(v=2.0 \mathrm{~m} / \mathrm{s})$ 


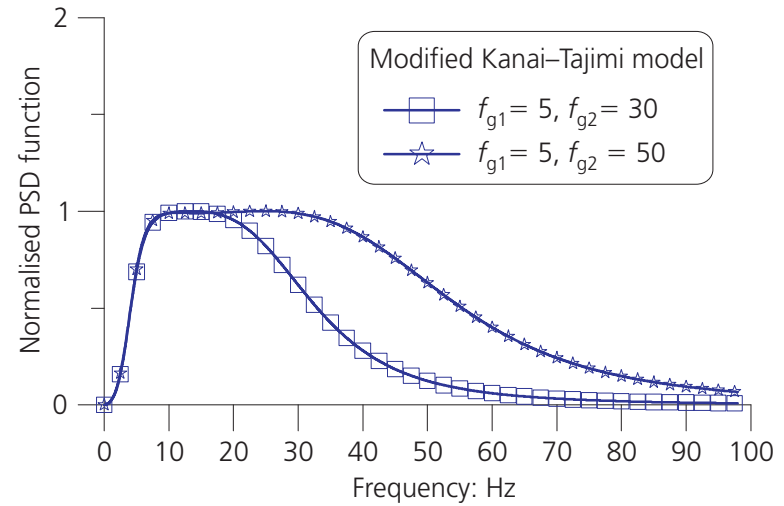

(a)

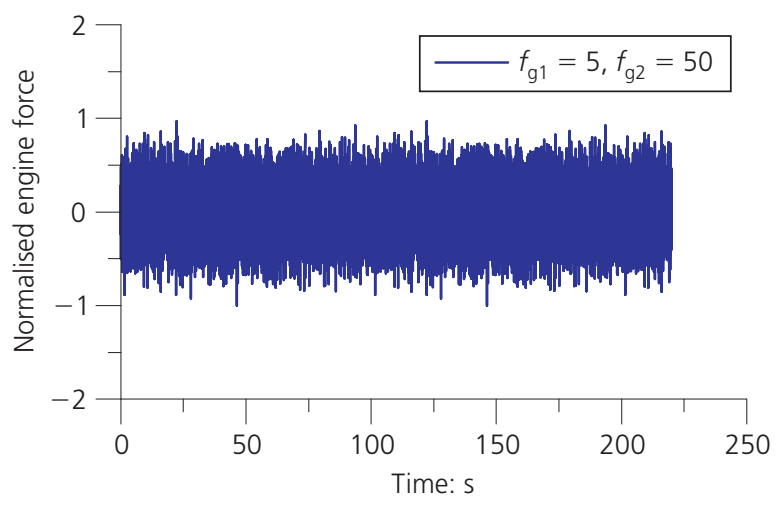

(b)

Figure 4. Simulated engine excitation force: (a) PSD spectra; (b) time history

Figure 5 shows that the trend of the spectra obtained with constant damping ratio and Rayleigh damping are consistent, and the floor vibration spectrum obtained using a constant damping ratio of $5 \%$ falls within the median values of these spectra. Therefore, the damping matrix of the continuous beam system that is simulated with a constant damping ratio $(5 \%)$ for each vibration mode is considered to be valid and was adopted in this study to simplify the task.

\subsection{Time history analysis of AGV-induced floor vibration}

In this study, the vibration level induced by a single AGV or AGVs in series (two or three AGVs) moving with $v=2.0 \mathrm{~m} / \mathrm{s}$ on the three-span continuous beam is assessed by considering $n=12$ modes. To examine the effect of the spacing $\left(l_{\mathrm{a}}\right)$ between any two consecutive $\mathrm{AGVs}$ on the floor vibration, the dynamic floor responses with AGV spacings of 3, 6, 9, 12, 15 and $18 \mathrm{~m}$ are compared. It should be noted that the maximum engine force of $F_{\max }=300 \mathrm{kgf}$ and frequency parameters $f_{\mathrm{g} 1}=5 \mathrm{~Hz}$ and $f_{\mathrm{g} 2}=50 \mathrm{~Hz}$ for the modified Kanai-Tajimi model are adopted to assess the AGV-induced floor vibration and the effectiveness of vibration control by energy dissipation. Thus, the AGV can be simulated as a pair of concentrated moving loads of

$$
P_{1}(t)=P_{2}(t)=P / 2+F(t) / 2
$$

separated at a distance of $1.2 \mathrm{~m}$.

Figure 6 illustrates the central acceleration time histories of the middle span at $x=54 \mathrm{~m}$ for a continuous beam subjected to a single AGV and three AGVs. The histories were obtained using the state-space procedure algorithm with $\Delta t=0.002 \mathrm{~s}$. The acceleration responses in the time domain are shown to have increased with the number of AGVs, and a smaller AGV spacing results in more pronounced floor vibrations. Moreover, the AGVinduced maximum floor velocity ratios (VRs) at various locations along the AGV bay are also explored. Figure 7 illustrates the maximum VRs at various locations (6 m uniformly spaced, except at the supports) of the three-span continuous beam subjected to AGV moving loads. It is noted that the maximum VR is defined as the ratio of overall maximum AGV-induced RMS velocity in the one-third octave band to the VC-B level of $0.0025 \mathrm{~cm} / \mathrm{s}$. A maximum VR value greater than 1.0 implies that the floor vibration exceeds the desired VC-B level. The results show that the floor vibrations exceeded the VC-B level regardless of the locations of the three-span continuous beam subjected to either single or multiple AGV moving loads, and the vibrations increased with decreased AGV spacing. Moreover, maximum VRs normally occur near to the central position of each span and may be as high as 3.14 for a single AGV, 6.38 for two AGVs and 9.57 when three AGVs with $l_{\mathrm{a}}=3 \mathrm{~m}$ are moving on the floor.

\subsection{Vibration control via passive energy-dissipation device}

Floor vibrations may be controlled by simply reducing the span length of the floor system. However, a recent study of the effect of span length on the floor vibration induced by a single AGV (Lee et al., 2012) indicated that span reduction does not effectively improve the overall micro-vibration performance in terms of the spectral response because the predominant frequencies of the span-reduced structures may be potentially in resonance with the major frequency contents of the AGV loads that span a broad bandwidth. Therefore, only the vibration control of long-span floors in a TFT-LCD factory using energy-dissipation devices (in particular VE dampers (or panels)) (Lee et al., 2005; Yohei et al., 2003) is examined in this study. Without loss of generality, the force of an equivalent linear VE damper with a stiffness, $k_{\mathrm{ve}}$, and damping, $c_{\mathrm{ve}}$, installed at the position $x_{\mathrm{d}}$ is represented as

$$
\begin{aligned}
F_{\mathrm{d}}\left(x_{\mathrm{d}}, t\right) & =k_{\mathrm{ve}} w\left(x_{\mathrm{d}}, t\right)+c_{\mathrm{ve}} \dot{w}\left(x_{\mathrm{d}}, t\right) \\
& =k_{\mathrm{ve}} \sum_{i=1}^{n} q_{i}(t) X_{i}\left(x_{\mathrm{d}}\right)+c_{\mathrm{ve}} \sum_{i=1}^{n} \dot{q}_{i}(t) X_{i}\left(x_{\mathrm{d}}\right)
\end{aligned}
$$

If a single VE damper is installed under a central position of the middle span $\left(x_{\mathrm{d}}=L / 2\right)$ and its damping force is regarded as an 


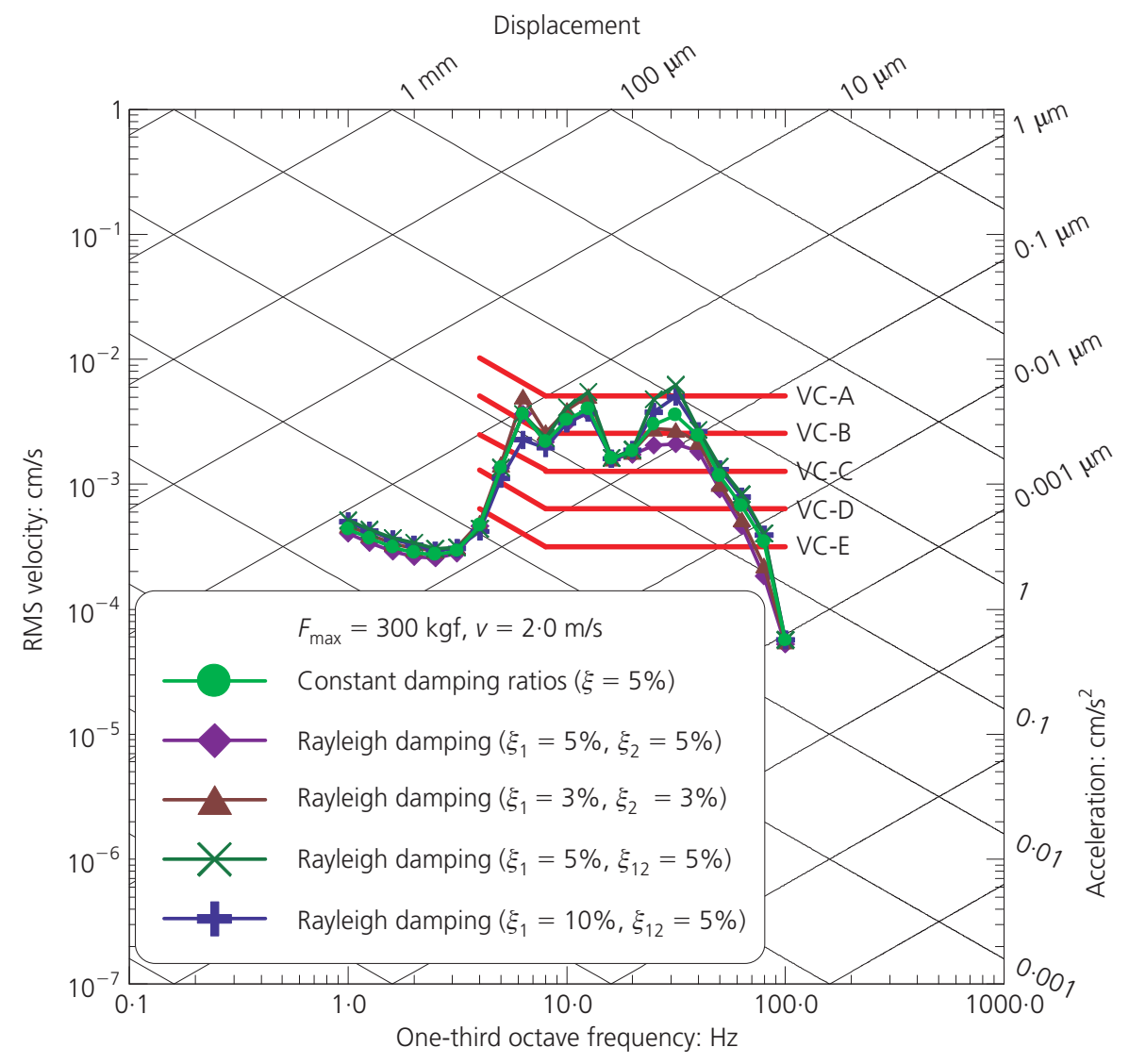

Figure 5. Comparison of floor vibration spectra (at $x=45 \mathrm{~m}$ )

obtained using constant and variable damping ratios for the vibration modes

external force, another term that is similar to the right-hand side of Equation 2 for the $j$ th generalised coordinate can be written as

$$
\begin{aligned}
F_{\mathrm{d}}(L / 2, t) X_{j}(L / 2)= & \left(k_{\mathrm{ve}} \sum_{i=1}^{n} q_{i}(t) X_{i}(L / 2)\right) X_{j}(L / 2) \\
& +\left(c_{\mathrm{ve}} \sum_{i=1}^{n} \dot{q}_{i}(t) X_{i}(x)\right) X_{j}(L / 2),
\end{aligned}
$$

16.

$$
j=1,2, \ldots, n
$$

The modal contributions of the VE damper on damping and stiffness, which are related to the global structural system, can be further elaborated from Equation 16 in matrix forms as 17b. $\mathbf{K}_{\mathrm{d}}=k_{\mathrm{ve}} \boldsymbol{X}\left(x_{\mathrm{d}}\right) \boldsymbol{X}^{\mathrm{T}}\left(x_{\mathrm{d}}\right), x_{\mathrm{d}}=L / 2$

in which

$$
\boldsymbol{X}\left(x_{\mathrm{d}}\right)=\left[\begin{array}{llll}
X_{1}\left(x_{\mathrm{d}}\right) & X_{2}\left(x_{\mathrm{d}}\right) & \cdots & X_{n}\left(x_{\mathrm{d}}\right)
\end{array}\right]^{\mathrm{T}}
$$

is the $n \times 1$ vibration mode vector at the damper location. From Equations 17a and 17b, the equation of motion (Equation 10a) of a Bernoulli-Euler beam implemented with a single VE damper to resist moving loads can then be expressed as

$$
\mathbf{M} \ddot{\boldsymbol{q}}(t)+\mathbf{C} \dot{\boldsymbol{q}}(t)+\mathbf{K} \boldsymbol{q}(t)=
$$

18a. $\mathbf{E} \boldsymbol{w}(t)-\left[\mathbf{C}_{\mathrm{d}} \dot{\boldsymbol{q}}(t)+\mathbf{K}_{\mathrm{d}} \boldsymbol{q}(t)\right]$

or

18b. $\mathbf{M} \ddot{\boldsymbol{q}}(t)+\left(\mathbf{C}+\mathbf{C}_{\mathrm{d}}\right) \dot{\boldsymbol{q}}(t)+\left(\mathbf{K}+\mathbf{K}_{\mathrm{d}}\right) \boldsymbol{q}(t)=\mathbf{E} \boldsymbol{w}(t)$ 


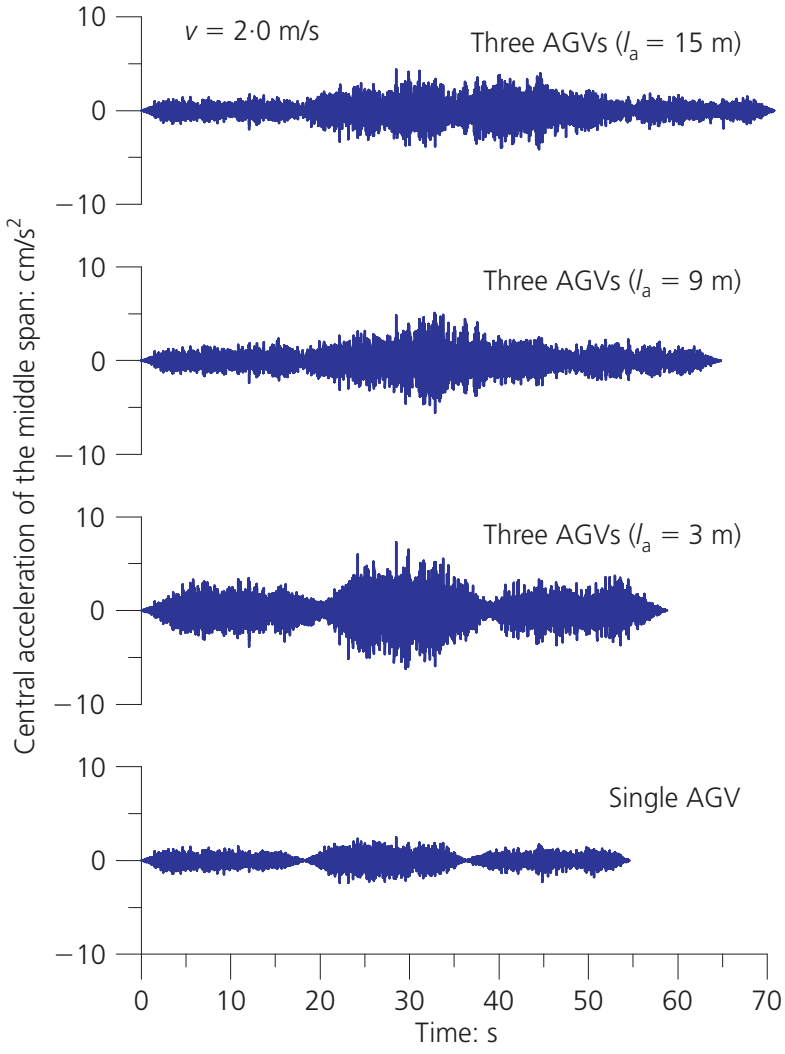

Figure 6. Central acceleration responses of the middle span with one and three AGVs

If multiple VE dampers are implemented at various locations along the continuous beam, as shown in Figure 2, Equation 18b can be further expressed as

$$
\begin{gathered}
\mathbf{M} \ddot{\boldsymbol{q}}(t)+\left\{\mathbf{C}+\sum_{i=1}^{\eta} c_{\mathrm{ve}}\left[\boldsymbol{X}\left(x_{\mathrm{d} i}\right) \boldsymbol{X}^{\mathrm{T}}\left(x_{\mathrm{d} i}\right)\right]\right\} \dot{\boldsymbol{q}}(t) \\
+\left\{\mathbf{K}+\sum_{i=1}^{\eta} k_{\mathrm{ve}}\left[\boldsymbol{X}\left(x_{\mathrm{d} i}\right) \boldsymbol{X}^{\mathrm{T}}\left(x_{\mathrm{d} i}\right)\right]\right\} \mathbf{q}(t)=\mathbf{E} \boldsymbol{w}(t)
\end{gathered}
$$

where $\eta$ is the number of VE dampers.

In this study, the damping and stiffness coefficients of the equivalent linear VE damper are determined through a parametric study by considering three AGVs with $l_{\mathrm{a}}=3 \mathrm{~m}$ moving on the continuous beam that was implemented with a single VE damper at $x_{\mathrm{d}}=54 \mathrm{~m}$, three VE dampers at $x_{\mathrm{d}}=18,54$ and $90 \mathrm{~m}$, and six VE dampers at $x_{\mathrm{d}}=12,24,48,60,84$ and $96 \mathrm{~m}$, as shown in Figure 2. The performance index $J$ is defined as the square of the sum of the maximum VRs at various locations (6 m uniformly spaced, except at the supports) along the three-span continuous beam as

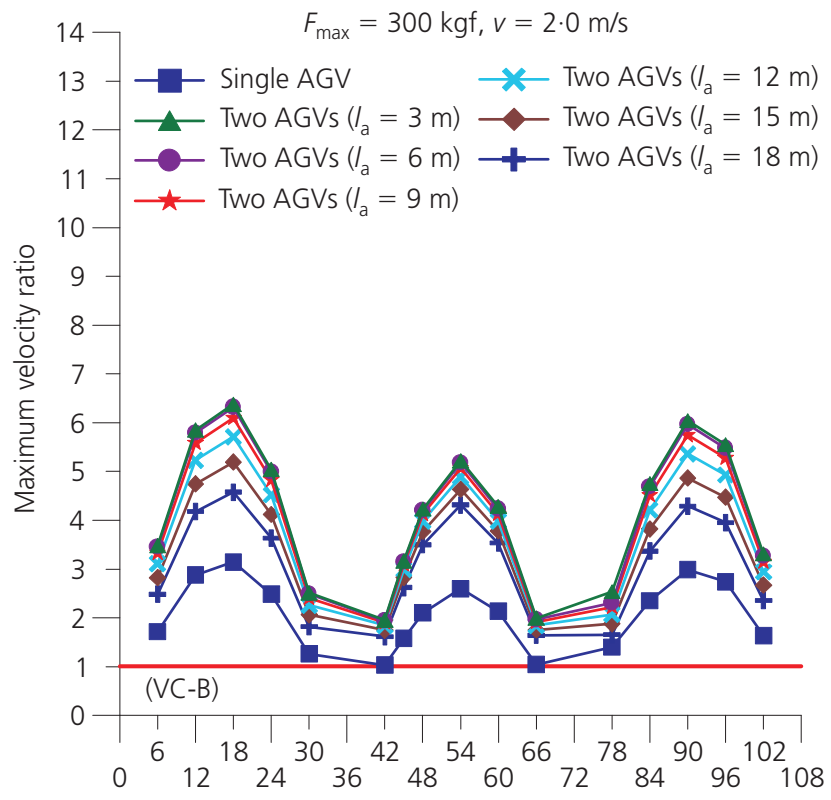

(a)

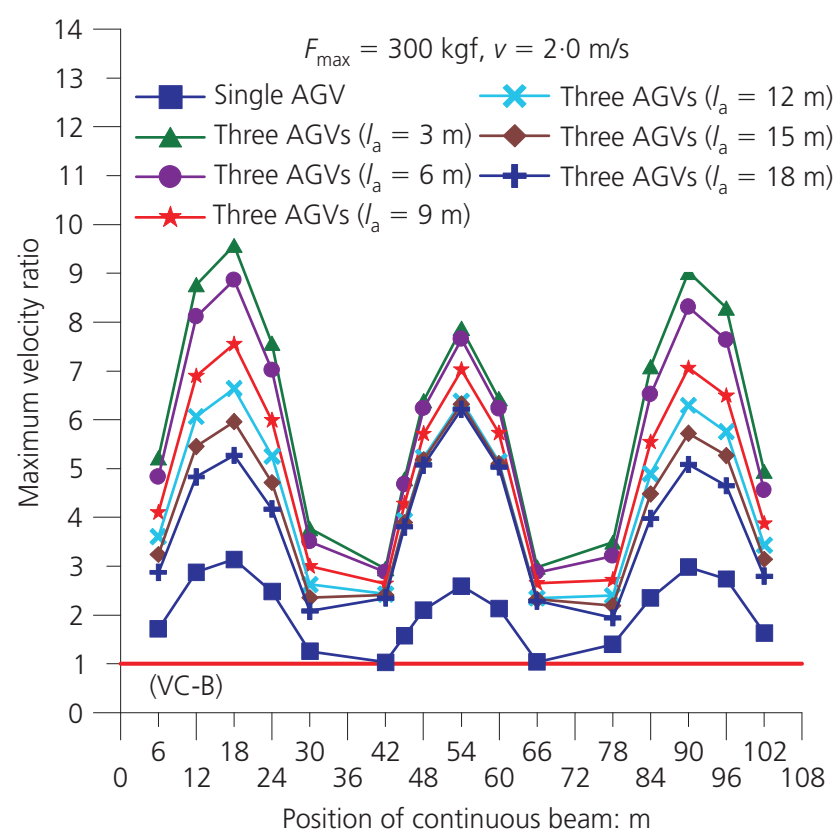

(b)

Figure 7. Effect of AGV spacing on maximum velocity ratios at various locations: (a) two AGVs; (b) three AGVs

$$
\begin{aligned}
J= & \left(\mathrm{VR}_{x=6}\right)^{2}+\left(\mathrm{VR}_{x=12}\right)^{2}+\cdots \\
& +\left(\mathrm{VR}_{x=96}\right)^{2}+\left(\mathrm{VR}_{x=102}\right)^{2}
\end{aligned}
$$$$
19 .
$$

The parametric study is performed by varying the stiffness coefficient between $1.0 \times 10^{3}$ and $1.0 \times 10^{8} \mathrm{~N} / \mathrm{m}$, and the damping coefficient between $1.0 \times 10^{3}$ and $1.0 \times 10^{7} \mathrm{~N} \mathrm{~s} / \mathrm{m}$, respectively. Figure 8 illustrates the effects of damper parameters on the 


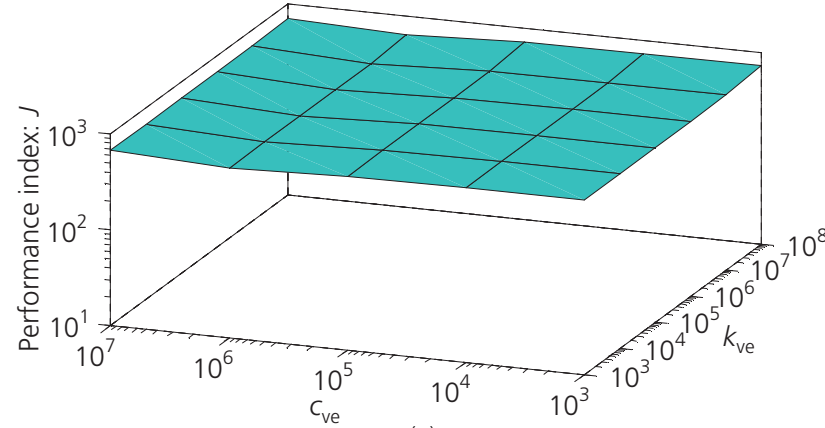

(a)

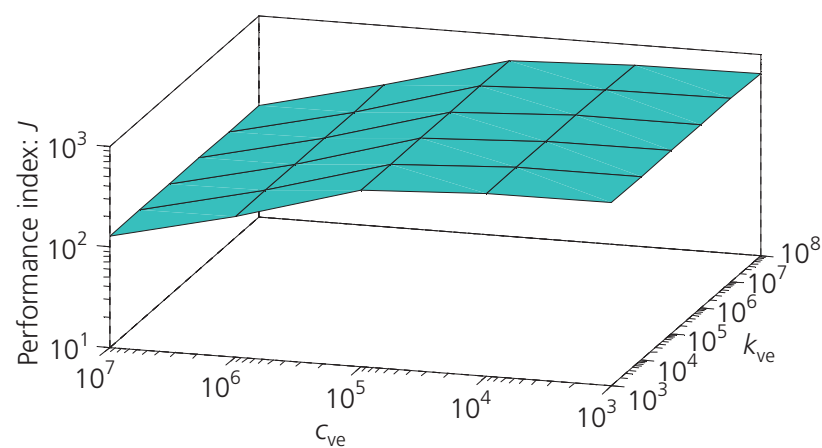

(b)

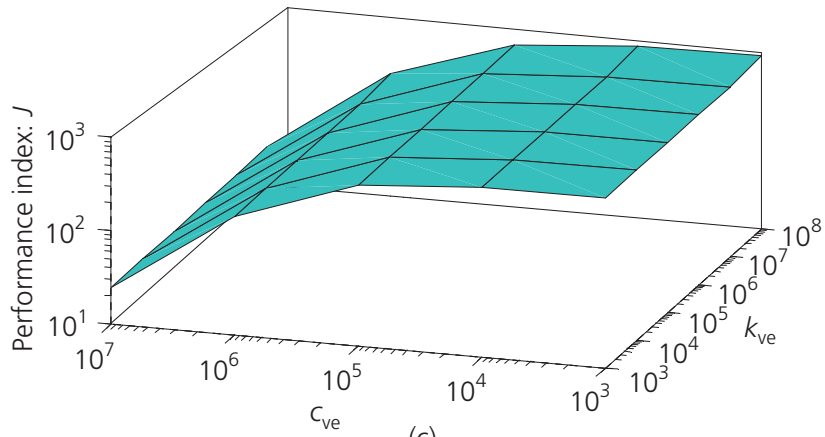

(c)

Figure 8. Effect of damper parameters on performance index (three $A G V s, l_{a}=3 \mathrm{~m}$ ): (a) single VE damper; (b) three VE dampers; (c) six VE dampers

performance index. With the exception of the case involving a single VE damper, $J$ decreases monotonically with increased damping for multiple VE dampers. Significant reductions in the performance index (at least 60\%) were achieved with six VE dampers implemented as $c_{\mathrm{ve}}>10 \times 10^{6}$. The stiffness coefficient is found to have a minor effect on the performance index for a fixed damping coefficient. The minimum performance index occurs at $c_{\mathrm{ve}}=10 \times 10^{7} \mathrm{~N} \mathrm{~s} / \mathrm{m}$, where the continuous beam becomes, however, a critically damped system. It is usually impractical to design a critically damped civil structure. Therefore, a damper with $c_{\mathrm{ve}}=7.0 \times 10^{6} \mathrm{~N} \mathrm{~s} / \mathrm{m}$ and $k_{\mathrm{ve}}=1.0 \times$ $10^{5} \mathrm{~N} / \mathrm{m}$ will be adopted for assessment of the effectiveness of vibration control.

Figure 9 shows the central floor vibration spectra of the middle

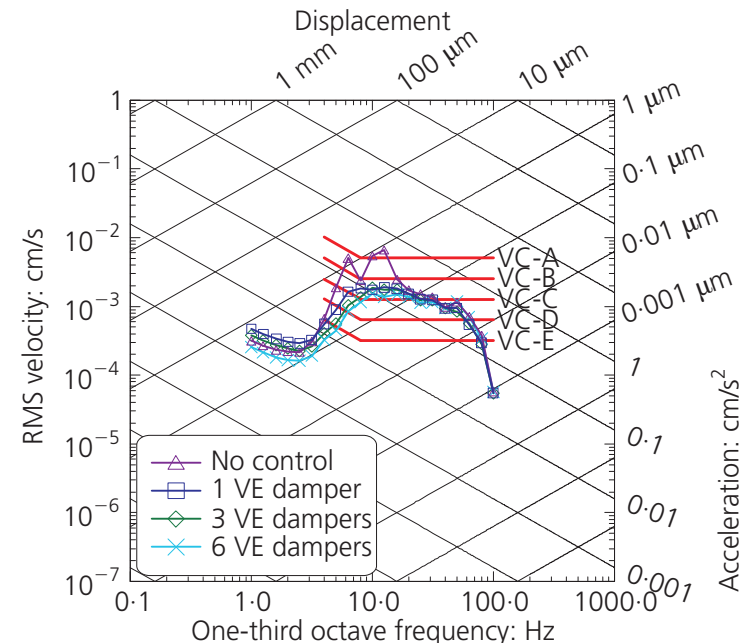

(a)

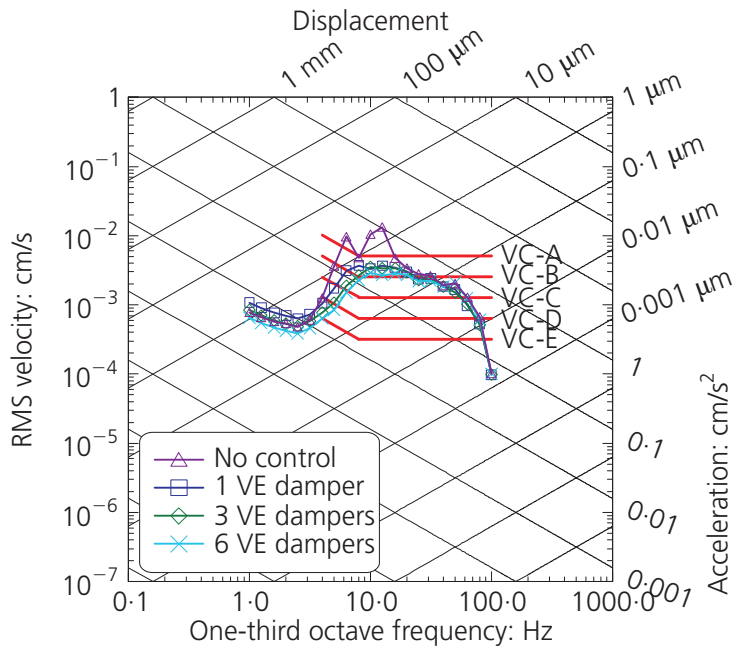

(b)

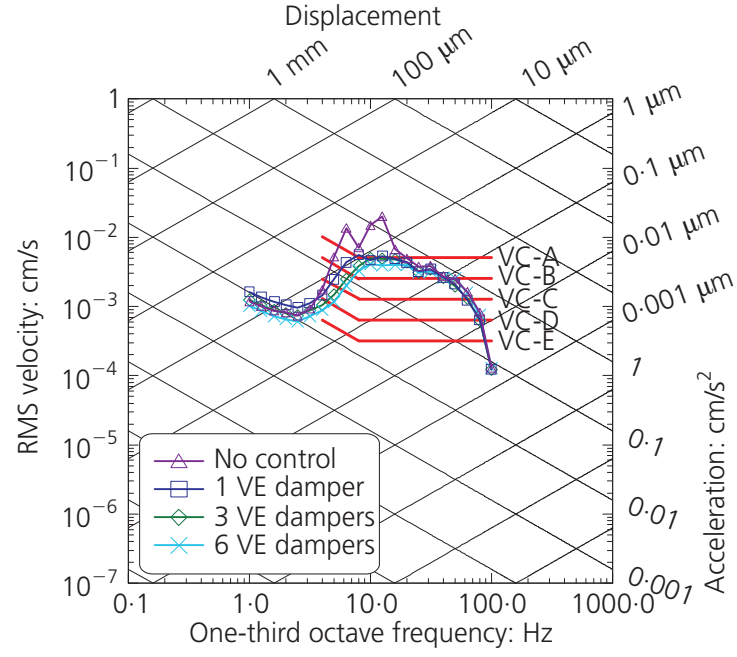

(c)

Figure 9. Effect of number of dampers on central floor vibration spectra of the middle span: (a) single AGV; (b) two AGVs $\left(I_{\mathrm{a}}=3 \mathrm{~m}\right)$; (c) three AGVs $\left(I_{\mathrm{a}}=3 \mathrm{~m}\right)$ 
span for varying numbers of AGVs (with a minimum spacing of $3 \mathrm{~m}$ ) and VE dampers. The central floor vibrations induced by a single AGV can be suppressed under the VC-B level with a reduction of $71-77 \%$ (Table 2), while those induced by two and three AGVs can only be reduced to be within the VC-B and VCA levels with a reduction of $72-78 \%$, and near the VC-A level with a reduction of $72-80 \%$, despite the fact that significant reductions in floor vibrations were realised by implementing multiple VE dampers. As shown in Table 1, the damping ratios of the three-span continuous beam that was implemented with a single VE damper at the middle of the central span $\left(x_{\mathrm{d}}=54 \mathrm{~m}\right)$ increase from $5 \%$ to $23.29 \%, 28.42 \%$ and $6.08 \%$ for the first, third and fifth modes, respectively, while those for the second and fourth modes remain at $5 \%$, because the VE damper is installed in the inflection point of the mode shapes. Increasing the number of $\mathrm{VE}$ dampers implemented at various locations along the continuous beam further enhances the damping ratios. For instance, the damping ratios of the first five modes of the continuous beam implemented with six VE dampers $\left(x_{\mathrm{d}}=12,24\right.$, $48,60,84$ and $96 \mathrm{~m}$ ) can be significantly enhanced to over $24 \%$, as shown in Table 1.

Figures 10-12 show the effects of the number of dampers and $\mathrm{AGV}$ spacing on the maximum VRs at various positions of the three-span continuous beam under AGV moving loads. The results show that an increased number of VE dampers results in more pronounced reductions in floor vibrations. If a single VE damper is implemented on the central span at $x_{\mathrm{d}}=54 \mathrm{~m}$, only the vibrations of the central span can be effectively reduced. However, in some cases, those of the side spans are amplified. In fact, the vibrations of the side spans are also governed by the second mode. The equivalent damping ratio of the second mode is unchanged for $x_{\mathrm{d}}=54 \mathrm{~m}$ (the inflection point of the second and fourth mode shapes). If the damping ratio of the second mode cannot be significantly enhanced, the maximum response of the side spans will not be effectively reduced, despite the fact that the damping ratio of the first mode has considerably increased. When three VE dampers are installed at the middle of each span, the maximum VRs can be further reduced. In this case, it is found that the damping ratio of the fourth mode remains at $5 \%$. If six VE dampers are installed at $x_{\mathrm{d}}=12,24,48,60,84$ and $96 \mathrm{~m}$, and the spacing of two and three AGVs is set by the vehicle

\begin{tabular}{lccc}
\hline \multirow{2}{*}{$\begin{array}{l}\text { Number of } \\
\text { VE dampers }\end{array}$} & \multicolumn{3}{c}{ Reduction in floor vibrations: \% } \\
\cline { 2 - 4 } & Single AGV & $\begin{array}{c}\text { Two AGVs } \\
I_{\mathrm{a}}=3 \mathrm{~m}\end{array}$ & $\begin{array}{c}\text { Three AGVs } \\
\mathrm{I}_{\mathrm{a}}=3 \mathrm{~m}\end{array}$ \\
\hline 1 & 71 & 72 & 72 \\
3 & 72 & 73 & 75 \\
6 & 77 & 78 & 80
\end{tabular}

Table 2. Percentage reduction in floor vibrations at central location of the middle span

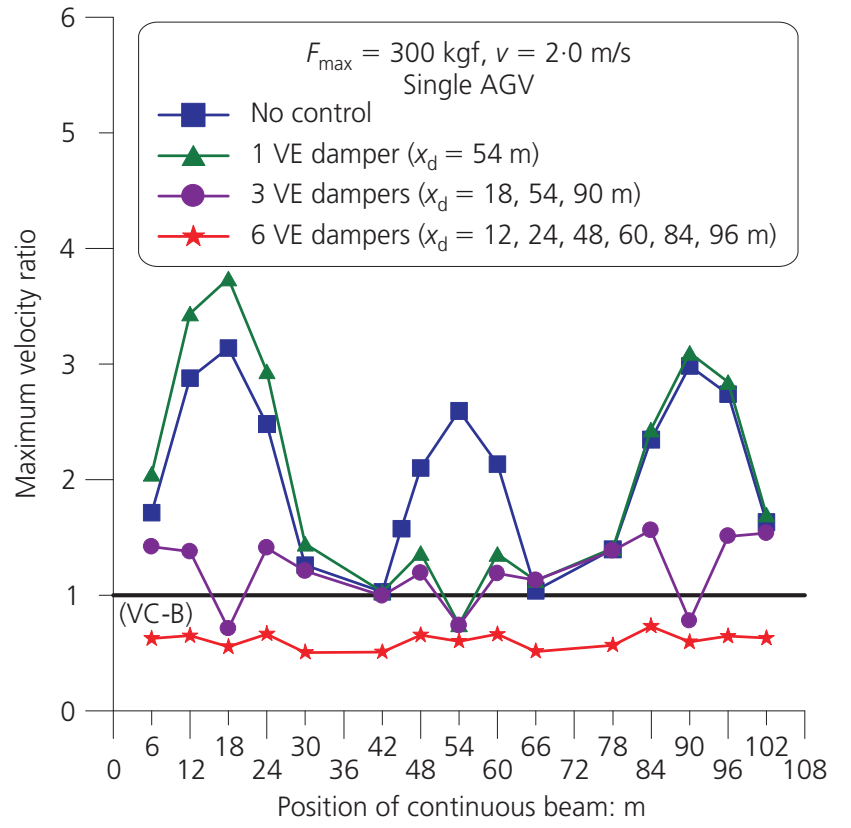

Figure 10. Effect of number of dampers on maximum velocity ratios for a single $A G V$

control system to be larger than $12 \mathrm{~m}$ and $18 \mathrm{~m}$, respectively, the maximum response of the entire continuous beam can be reduced to meet the VC-B vibration level, as shown in Figures 11 and 12.

\section{Conclusion}

This study explored AGV-induced vertical vibration on long-span floors of a TFT-LCD manufacturing factory. To allow quick assessment of AGV-induced floor micro-vibrations, a reduced sub-structural model that uses only the AGV moving bay without the need to construct a finite-element model of the entire storey was developed. This was done by considering the AGVs as a sequence of moving loads on an equivalent multiple-span continuous beam. The state-space procedure was adopted to achieve the desired numerical stability and accuracy in high-frequency responses.

The effectiveness of vibration mitigation using VE dampers was also examined. Simulation results indicate good agreement between the predicted and in situ measured floor vibration spectra, and the simulated AGV-induced floor vibrations without control exceed the acceptable VC-B vibration level that is required for the installation of some specific precision process tools in the TFT-LCD industry, regardless of the number of AGVs that are in motion on the floor. On the other hand, the application of energydissipation devices has shown to be promising in the control of AGV-induced floor vibrations, as they enhance the damping characteristics of a multi-span floor system. The maximum response of the whole continuous beam when induced by a sequence of AGV moving loads can be suppressed to the desired VC-B level if proper locations of multiple VE dampers are implemented and if the specific distances between any two 


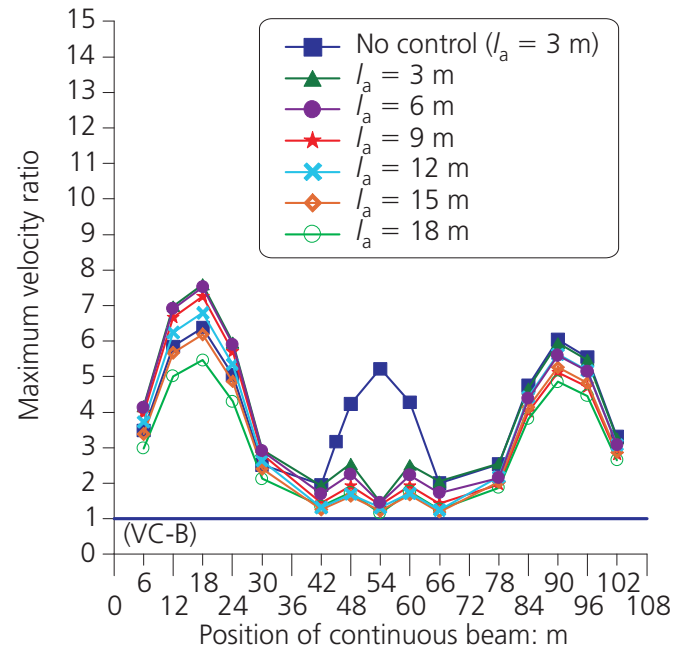

(a)

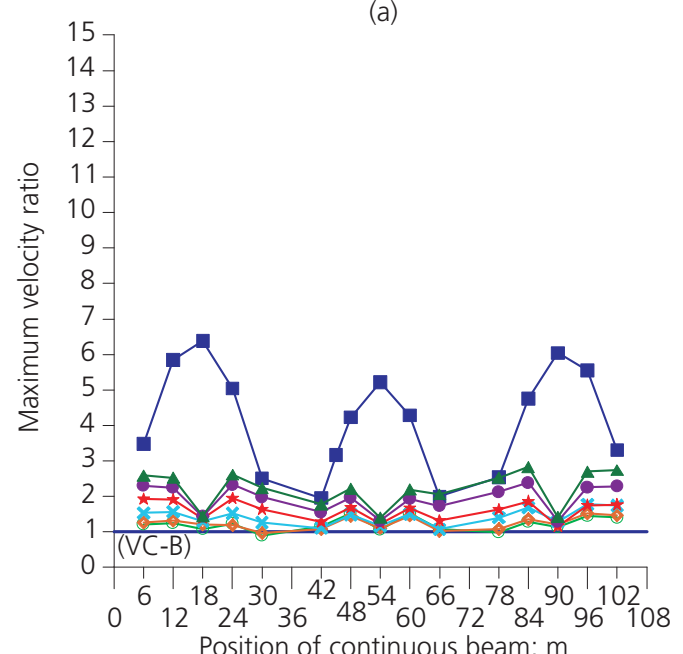

(b)

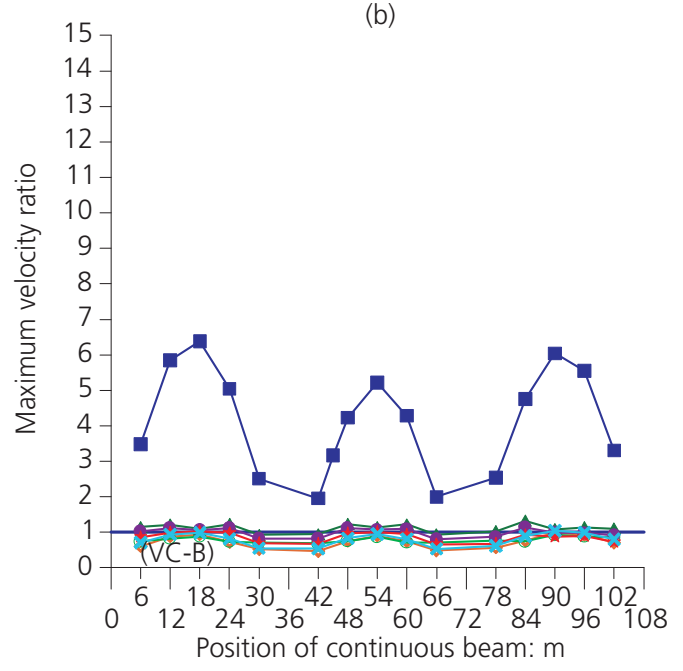

(c)

Figure 11. Effect of number of dampers on maximum velocity ratios for two AGVs: (a) single VE damper $\left(x_{d}=54 \mathrm{~m}\right)$; (b) three VE dampers $\left(x_{d}=18,54\right.$ and $\left.90 \mathrm{~m}\right)$; (c) six VE dampers $\left(x_{d}=12\right.$, $24,48,60,84$ and $96 \mathrm{~m}) . F_{\max }=300 \mathrm{kgf}, v=2.0 \mathrm{~m} / \mathrm{s}$
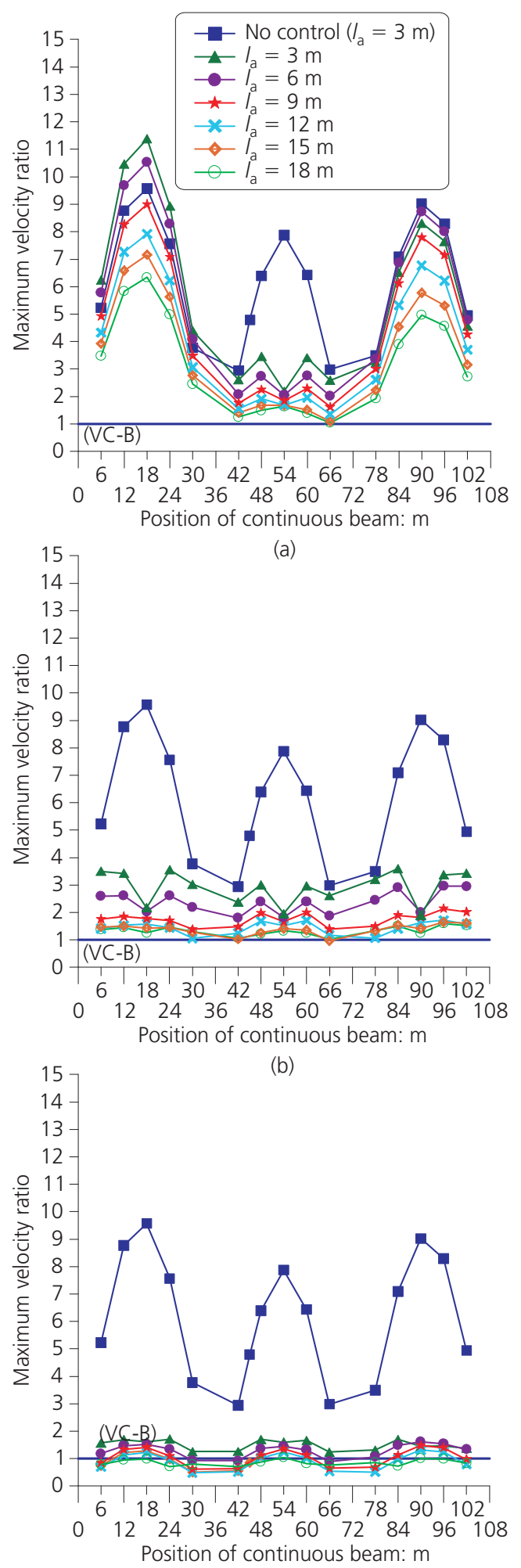

(c)

Figure 12. Effect of number of dampers on maximum velocity ratios for three AGVs: (a) single VE damper $\left(x_{d}=54 \mathrm{~m}\right)$; (b) three VE dampers $\left(x_{d}=18,54\right.$ and $\left.90 \mathrm{~m}\right)$; (c) six VE dampers $\left(x_{d}=12\right.$, $24,48,60,84$ and $96 \mathrm{~m}) . F_{\max }=300 \mathrm{kgf}, v=2.0 \mathrm{~m} / \mathrm{s}$ 
consecutive AGVs is adjusted such that $l_{\mathrm{a}} \geqslant 12 \mathrm{~m}$ for two AGVs and $l_{\mathrm{a}} \geqslant 18 \mathrm{~m}$ for three AGVs moving on the production floors of the target TFT-LCD factory. From a practical point of view, the proposed simplified procedure for the rapid assessment of the level of AGV-induced floor vibrations may be a good alternative during the preliminary design phase of new floor systems and for a quick evaluation of existing production floor systems in hightechnology factories.

\section{Acknowledgements}

The research described here was supported by the Research Grants Council of the Hong Kong SAR (project no. HKU7166/ 08E) and The University of Hong Kong (small project funding, project code 201007176174).

\section{REFERENCES}

Amick H and Bayat A (1998) Dynamics of stiff floors for advanced technology facilities. Proceeding of the 12th ASCE Engineering Mechanics Conference, La Jolla, CA, USA. ASCE, Reston, VA, USA, pp. 318-321.

Amick H, Hardash S, Gillett P and Reaveley RJ (1991) Design of stiff low-vibration floor structures. Proceedings of International Society for Optical Engineering (SPIE) 1619, San Jose, CA, USA. SPIE, Bellingham, WA, USA, pp. $180-191$.

Chopra AK (1995) Dynamics of Structures: Theory and Applications to Earthquake Engineering. Prentice Hall, Upper Saddle River, NJ, USA.

Gordon CG (1987) The design of low-vibration buildings for microelectronics and other occupancies. Proceedings of International Society for Optical Engineering (SPIE) 732, London, UK. SPIE, Bellingham, WA, USA, pp. 2-10.

Gordon CG (1991) Generic criteria for vibration sensitive equipment. Proceedings of International Society for Optical Engineering (SPIE) 1619, San Jose, CA, USA. SPIE, Bellingham, WA, USA, pp. 71-85.

Housner GW, Bergman LA, Caughey TK et al. (1997) Special issue, structural control: past, present, and future. Journal of Engineering Mechanics, ASCE 123(9): 897-971.

Howard CQ and Hansen CH (2003) Vibration analysis of waffle floors. Computers and Structures 81(1): 15-26.

Ismail M, Rodellar J and Ikhouane F (2009) An innovation isolation bearing for motion-sensitive equipment. Journal of Sound and Vibration 326(3-5): 503-521.

Jang YJ and Choi GH (2006) Introduction to automated material handling systems in LCD panel production lines. Proceedings of the 2006 IEEE International Conference on Automation Science and Engineering, Shanghai. IEEE, New York, NY, USA, pp. 223-229.

Ju SH (2009) Finite element investigation of traffic induced vibrations. Journal of Sound and Vibration 321(3-5): 837-853.

Kim JJ and Amick H (1997) Active vibration control in fabs. Semiconductor International 20(8): 223-228.

Lee CL, Wang YP and Su RKL (2012) A study on AGV-induced floor micro-vibration in TFT-LCD high technology fabs. Structural Control and Health Monitoring 19(3): 451-471. Lee HP (1996) Dynamic response of a Timoshenko beam subjected to a moving mass. Journal of Sound and Vibration 198(2): 249-256.

Lee KS, Fan CP, Sause R and Ricles J (2005) Simplified design procedure for frame buildings with viscoelastic or elastomeric structural dampers. Earthquake Engineering Structural Dynamics 34(10): 1271-1284.

Lopez-Almansa F, Harbat AH and Rodellar J (1988) SSP algorithm for linear and nonlinear dynamic response simulation. International Journal of Numerical Methods in Engineering 26(12): 2687-2706.

Nakamura Y, Nakayama M, Masuda K et al. (1999) Development of 6-DOF microvibration control system using giant magnetostrictive actuator. Proceedings of International Society for Optical Engineering (SPIE) 3671, Newport Beach, CA, USA. SPIE, Bellingham, WA, USA, pp. 229-240.

Pan TC, Mita A and Li L (2008) Evaluation of floor vibration in a biotechnology laboratory caused by human walking. Journal of Performance of Constructed Facilities, ASCE 22(3): 122-130.

Pan TC, Mita A and Li L (2001) Vehicle-induced floor vibration in a multistory factory building. Journal of Performance of Constructed Facilities, ASCE 15(2): 54-61.

Pavic A and Reynolds P (2002) Vibration serviceability of long-span concrete building floors: part 1 - review of background information. Shock and Vibration Digest 34(3): 191-211.

Pavic A and Reynolds P (2003) Evaluation of mathematical models for predicting walking-induced vibrations of highfrequency. International Journal of Structural Stability Dynamics 3(1): 107-130.

Soong TT and Dargush GF (1997) Passive Energy Dissipation Systems in Structural Engineering. Wiley, New York, NY, USA.

Ungar EE and White RW (1979) Footfall-induced vibrations of floors supporting sensitive equipment. Sound and Vibration 13(10): 10-13.

Ungar EE, Zapfe JA and Kemp JD (2004) Predicting footfallinduced vibration of floors. Sound and Vibration 38(11): $16-22$.

Wang YP, Lee CL and Yo TH (2001) Modified state-space procedures for pseudodynamic testing. Earthquake Engineering and Structural Dynamics 30(1): 59-80.

Willford M, Young P and Field C (2005) Improved methodologies for the prediction of footfall-induced vibration. Proceedings of International Society for Optical Engineering (SPIE) 5933, San Diego, CA, USA. SPIE, Bellingham, WA, USA, pp. 206-217.

Wu JJ (2003) Use of equivalent beam models for the dynamic analyses of beamplates under moving forces. Computers and Structures 81(30/31): 2749-2766.

Wu JS and Dai CW (1987) Dynamic responses of multispan 
nonuniform beam due to moving loads. ASCE Journal of Structural Engineering 113(13): 458-474.

Wu JS and Shih PY (2000) Dynamic response of a railway and carriage under the high-speed moving loads. Journal of Sound and Vibration 236(1): 61-87.

Xu YL and Guo AX (2006) Microvibration control of coupled high tech equipment-building systems in vertical direction. International Journal of Solids and Structures 43(21): 65216534.

Xu YL and Hong XJ (2008) Stochastic modelling of trafficinduced building vibration. Journal of Sound and Vibration 313(1/2): 149-170.

Xu YL, Liu HJ and Yang ZC (2003a) Hybrid platform for vibration control of high-tech equipment in building subject to ground motion. Part 1: Experiment. Earthquake Engineering and Structural Dynamics 32(8): 1185-1200.

Xu YL, Yang ZC, Chen J, Liu HJ and Chen J (2003b) Microvibration control platform for high technology facilities subject to traffic-induced ground motion. Engineering Structures 25(8): 1069-1082.

Xu YL, Guo AX, Li H and Ng CL (2004) Hybrid control of microvibration of high tech facility under horizontal and vertical ground. Proceedings of International Society for Optical Engineering (SPIE) 5391, San Diego, CA, USA. SPIE, Bellingham, WA, USA, pp. 50-60.

Yang YB and Lin BH (1995) Vehicle-bridge interaction analysis by dynamic condensation method. Journal of Structural Engineering, ASCE 121(11): 1636-1643.

Yang YB and Yao JD (1997) Vehicle-bridge interaction element of dynamic analysis. Journal of Structural Engineering, ASCE 123(11): 1512-1518.
Yang JN and Agrawal AK (2000) Protective systems for hightechnology facilities against microvibration and earthquake. Journal of Structural Engineering and Mechanics 10(6): $561-575$.

Yang ZC, Xu YL, Chen J and Liu HJ (2003) Hybrid platform for vibration control of high-tech equipment in building subject to ground motion. Part 2: Analysis. Earthquake Engineering and Structural Dynamics 32(8): 1201-1215.

Yang YB, Yao JD and Wu YS (2004) Vehicle-Bridge Interaction Dynamics: With Applications to High-Speed Railways. World Scientific, Singapore.

Yao JD and Yang YB (2006) Vertical acceleration of simple beams due to successive loads traveling at resonant speeds. Journal of Sound and Vibration 289(1/2): 210-228.

Yoshioka H, Takahashi Y, Katayama K, Imazawa T and Murai N (2001) An active microvibration isolation system for hi-tech manufacturing facilities. Journal of Vibration and Acoustics, ASME 123(2): 269-275.

Yohei S, Yoji O, Kazuhiko K and Osamu T (2003) Velocitydependent damper performance test under extremely small response. Summaries of Technical Papers of Annual Meeting Architectural Institute of Japan. B-2, Structures II, Structural Dynamics Nuclear Power Plants, AIJ, Tokyo, Japan, pp. 813814 (in Japanese).

Zheng DY, Cheung YK, Au FTK and Cheng YS (1998) Vibration of multi-span non-uniform beams under moving loads by using modified beam vibration functions. Journal of Sound and Vibration 212(3): 455-467.

Živanović S and Pavić A (2009) Probabilistic modeling of walking excitation for building floors. Journal of Performance of Constructed Facilities, ASCE 23(3): 132-143.

\section{WHAT DO YOU THINK?}

To discuss this paper, please email up to 500 words to the editor at journals@ice.org.uk. Your contribution will be forwarded to the author(s) for a reply and, if considered appropriate by the editorial panel, will be published as a discussion in a future issue of the journal.

Proceedings journals rely entirely on contributions sent in by civil engineering professionals, academics and students. Papers should be 2000-5000 words long (briefing papers should be 1000-2000 words long), with adequate illustrations and references. You can submit your paper online via www.icevirtuallibrary.com/content/journals, where you will also find detailed author guidelines. 